\title{
Blood donor behaviour, motivations and the need for a systematic cross- cultural perspective: The example of moral outrage and health and non- health based philanthropy across seven countries
}

Eamonn Ferguson ${ }^{1 *}$, Laszlo Dorner ${ }^{2}$, Christopher R France ${ }^{3}$, Janis L France ${ }^{3}$, Barbara Masser ${ }^{4,5}$, Michael Lam ${ }^{4}$, Elena Marta ${ }^{6}$, Sara Alfieri ${ }^{6}$, Eva-Maria Merz ${ }^{7,8}$, Byron Adams ${ }^{9}$, Elisabeth Huis in 't Veld ${ }^{7,9}$, Josianne Scerri ${ }^{10,11}$

1. University of Nottingham, Nottingham, UK

2. Eszterházy Károly University, Eger, Hungary

3. Ohio University, USA

4. School of Psychology, The University of Queensland, Brisbane, Australia

5. Clinical Services and Research, Australian Red Cross Blood Service, Brisbane, Australia

6. Università Cattolica del Sacro Cuore, Italy

7. Sanquin, Amsterdam, the Netherlands

8. Vrije Universiteit, Amsterdam, the Netherlands

9. Tilburg University, Tilburg, the Netherlands

10. University of Malta, Malta

11. University of London, UK

*Corresponding Author. Email: eamonn.ferguson@nottingham.ac.uk

Conflict of Interests: None

Financial support: None

Acknowledgements: EF conceived on the initial study and design. All the co-authors contributed to the final design, and all authors collected the data. EF analysed the data and wrote the initial draft. All co-authors commented on the analyses and contributed significantly to the subsequent drafts of the paper. 


\begin{abstract}
Background: Blood donation is a prosocial altruistic act that is motived by the mechanisms that underlie altruism (e.g., warm-glow, reciprocity, fairness/trust). Because there is consistent evidence that altruism and its mechanisms show cross-cultural variability, in the present paper we make the case for a cross-cultural perspective in blood donor research.

Methods: We analyse a subset of variables from a larger study, with samples drawn from seven countries (England, Malta, the Netherlands, Australia, USA, Hungary, Italy: average N per country $=282$ ). This subset of variables focuses on health (organ donor registration) and non-health (volunteering, donating money) philanthropy, family traditions of helping, and moral outrage as predictors of blood donor status.
\end{abstract}

Results: We show two cross-cultural universals: 1) organ donor registration in opt-in countries is positively associated with blood donor status and 2) non-health philanthropy is generally unrelated to blood donor status. We also show two country specific effects: 1) a family tradition for helping is associated with blood donor status in Italy only and 2) moral outrage is a predictor only in the USA.

Conclusions: We contend that these findings provide proof of principle why a cross-cultural perspective on blood donor behaviour is needed. 


\section{Introduction}

Blood donation is at its core a prosocial act, motivated by a variety of mechanisms associated with altruism [1-2]. That is, the donor voluntarily gives a costly gift of blood to a stranger who benefits directly. Recent work has shown that mechanisms of altruism such as warm-glow, reciprocity, and norms of fairness are endorsed more by blood donors than nondonors [3-5]. Furthermore, there is now very strong and replicable evidence that altruism and prosociality vary across cultures [6]. Indeed, specific mechanisms of altruism, such as trust [7-8], reciprocity [9], honesty [10], cooperation and altruistic punishment [11], and antisocial punishment [12] are known to vary cross-culturally. Prosocial emotions such as gratitude [13] and prosocial traits such as agreeableness [14-15] also vary cross-culturally. Indeed, and more fundamentally, what people mean by prosocial or altruism is also culturally instantiated [16]. For example, it has been reported that Black, Asian and Ethnic Minority (BAME) communities have a conceptualization of altruism that focuses on reciprocity within the community, rather than helping strangers which is the dominant conceptualization in Western non-BAME communities [16]. Finally, the behavioural norms that regulate such behaviour show cross-cultural variability at the level of brain activity [17-18]. This growing evidence base of cross-cultural variation in altruism means that a deeper understanding of the motivations, and interpretation of blood donation behaviour, cannot be accomplished in cultural isolation. Indeed, work on blood donor behaviour needs to incorporate direct crosscultural comparison by design. This type of comparative work has started to emerge in the organ donation literature [19-20] but similar efforts are currently lacking within the blood donation literature.

There have been many attempts to explore motivations and barriers to blood donation in different cultures and ethnic groups, but these have been isolated one-off studies [e.g., 2122). Across these studies the predominant expressed motivation has been prosociality and altruism, [30] and no unique culturally-specific motivators have been identified [23-29]. However, as the meaning of altruism varies across cultures we do not know if everyone is conceptualizing altruism in the same way [16]. Furthermore, direct comparison across these studies is problematic as they typically use different methods, different measures, and different definitions of constructs. In contrast, work that applies the same methodologies, measures and sampling frames across cultures and countries allows for direct comparison, and hence cross-cultural consistencies (universals) and inconsistencies can be explored. This approach can also negate problems associated with taking work conducted in one culture, 
usually a Western, Educated, Industrialized, Rich, and Democratic (WEIRD) sample [6], and applying it to other cultural and ethnic groups.

To start to make the case for a cross-cultural perspective as a standard practice in blood donor research, the present manuscript presents data collected on blood donor behaviour from seven different countries using standardized protocols. Specifically, we collected data on economic games designed to explore altruism behaviourally, emotional predictors of prosociality, as well as data on blood donor status, organ donor status and a variety of non-health based philanthropy. By way of example, here we report on a subset of measures as predictors of blood donor status in each country.

\section{Blood Donation and Health and Non-Health Based Philanthropy}

There is evidence that blood and organ donation are associated with each other but that this is a small effect [31]. With respect to non-health philanthropy (e.g., volunteering, donating money) the evidence is that blood donors tend to engage in these forms of philanthropy less often than non-blood donors [4-5, 32]. But are these relationships crossculturally stable? To explore this question we distinguish other prosocial acts in terms of (1) health vs non-health [33] and (2) donating money or time/effort [34]. Finally, a family tradition of giving and helping is known to influence the prosociality of children and as such we explore the wider influences of family traditions for prosociality [35].

\section{Moral Outrage}

There is a growing literature that people are motivated to help, in general, because of specific negative emotional processes linked to perceived unfairness/injustice [36-37]. This perceived unfairness with respect to how others are treated is termed moral outrage and linked to prosocial engagement [37]. Moral outrage motivates people to want to effect prosocial change to maintain their self-image as a good person and/or change the social group or society for the better [38-40]. It has been argued that such moral outrage may motivate some people to donate blood as they perceive an inequality/unfairness in a system wherein the entire population is able to receive blood from the donations of a small minority $[1,5]$. 


\section{Methods}

\section{Participants and Sampling}

Data were collected in universities from seven countries (England, Malta, the Netherlands, Australia, USA, Hungary, Italy: See Tables 1 and 2 for details). This is part of a larger preregistered study (https://osf.io/5kzuu/) initiated at the University of Nottingham in England. Countries were selected to vary in term of blood donor practices, they also have a wide range of GDP per capita. They were also categorized using the World Giving Index (WGI) classification of philanthropy in each country for 2016 [41]. The WGI 2016 survey assesses 3 types of general helping (helping a stranger, donating money and volunteering time) across 139 countries with representative sample of 1000 people interviewed in each country. The three questions asked if the participant had: (1) "Helped a stranger, or someone you didn't know who needed help?", (2) "Donated money to a charity?" and (3) "Volunteered your time to an organisation?" The three are averaged to get an overall score. Categorizing countries in term of these WGI parameters is important for this project as they link directly to donating blood (giving to a stranger) and playing economic games (donating money) and general helping (volunteering) which are the main foci of this program of research.

While volunteer status, donating to a stranger, haemoglobin testing and bio-medical screening of blood were consistent across the donation systems there was also variability. In Hungary and Italy donors get paid time off from work. In Australia and the USA paid time off work is at the discretion of the employer and as such not a cultural help norm about blood donation in these countries. Travel can be paid in the Netherlands, and gifts are offered in the Netherlands, USA and Hungary. In terms of organ donor registration, England, Malta, the Netherlands, Australia, USA, and, Italy use an opt-in default and Hungary uses an opt-out default. The USA is ranked the highest in the WGI and Hungary the lowest, which is mirrored in GDP per capita.

All samples comprised students enrolled at University and all students completed an identical series of background demographic questions, behavioural economic games and psychometric assessments. A standard operating procedure (SOP) was issued to all participating University partners to ensure that the same measures were delivered in the same order. Some were delivered online and some via paper and pencil (see Table 2). Evidence shows that the variation in mode of delivery - internet vs paper and pencil - does not affect 
participant responding [42-43]. All measures were translated and then back-translated to ensure that the meaning was retained. In the larger study participants also played a number of economic games to explore donor motivation. Apart from in Italy these were incentivised using a conditional lottery mechanism. That is, all participants were told to treat the games as they were playing for real money as two participants in each country would be selected and paid based on their responses.

\section{Materials}

While the preregistered study has a specific focus on the nature of intrinsic motivation to donate blood, for this paper we focus on a subset of questions on other prosocial behaviours (health and non-health: detailed below) and moral outrage.

Blood Donor Status: We asked if the participant had ever donated blood (Yes or No). This is a standard and reliable index to identify blood donor status [4-5, 44].

Other Pro-social Acts: Participants also responded (Yes or No) to questions regarding: (1) a family tradition of helping ("Are your close family members involved in any form of charity work"), (2) effortful helping ("Have you ever considered giving up your time to help others by volunteering for charitable work"), (3) financial helping ("I have donated money), and (4) other health philanthropy ("I am on the organ donors register"). These questions have also been used in previous research [5] and evidence shows that people are reasonably accurate when indicating whether they have ever donated or not [44-45]. We did not examine organ donor registration in Hungary as it has an opt-out system rather than the opt-in system that operates in all of the other countries [46] and our assessments asks about actively registering rather than actively de-registering.

Moral Outrage. This was assessed by a four item index as part of the Deontic Justice Scale [47], which includes items such as "I feel sad when I see others being unfairly treated". Each item is responded to on a 5 point scale $(1=$ strongly disagree and $5=$ strongly agree $)$ and high scores equate to feeling saddened and concerned at the unfair and unjust treatment of others. In this study the scale showed a high level of internal consistency for the total sample $(\alpha=.87)$. 


\section{Results}

Initially, we examined the zero-order correlations ( $\varphi$ for two dichotomous variables, Somers' $d$ when the outcome is ordered and the predictor is continuous) for each of the seven countries and observed the following different patterns. The sample sizes across the countries ranged from 181 to 470 . The minimum $\mathrm{N}$ of 181 provides $80 \%$ power with an $\alpha$ of .05 to detect a small-to-medium correlation of .205 and the maximum $\mathrm{N}$ enables to detect a relatively small correlation of .128 .

- England: Significant associations with blood donor status were observed for: (1) Sex ( $\varphi$ $=.14, p=.017),(2)$ age (Somers' $\mathrm{d}=.13, p=.000)$, and (3) organ donor registration $(\varphi$ $=.15, p=.009)$. Blood donors were more likely male, older, and on the organ donor register.

- Hungary: Significant associations with blood donor status were observed for: (1) Sex ( $\varphi$ $=.21, p=.002),(2)$ age (Somers' $\mathrm{d}=.09, p=.038)$ and (3) effortful helping $(\varphi=-.13, p$ $=.06$ ). Blood donors were more likely male, older, and less likely to have volunteered.

- USA: Significant associations with blood donor status were observed for: (1) organ donor registration $(\varphi=.15, \mathrm{p}=.002)$, and (2) moral outrage (Somers' $\mathrm{d}=.08, p=.024)$. Blood donors were more likely to be on the organ donor register and more likely to report moral outrage.

- The Netherlands: Significant associations with blood donor status were observed for: (1) age (Somers' $d=.07, p=.01),(2)$ organ donor registration status $(\varphi=.17, p=.002)$, and (3) financial help $(\varphi=-.11, p=.047)$. Blood donors were more likely to be older, on the organ donor register, and less likely to have offered financial help.

- Italy: Significant associations with blood donor status were observed for: (1) age (Somers' $\mathrm{d}=-.07, p=.031)$, (2) organ donor registration $(\varphi=.22, p=.000)$, (3) family tradition $(\phi=.19, p=.001)$, (4) effortful helping ( $\varphi=.16, p=.004)$, and (5) financial help $(\varphi=.12, p=.029)$. Blood donors were more likely to be older, on the organ donor register, have a family member involved in charity work, and to have volunteered and donated money.

- Malta: Significant associations with blood donor status were observed for: (1) $\operatorname{sex}(\varphi=$ $.14, p=.046)$, and (2) organ donor registration $(\varphi=.22 p=.001)$. Blood donors were more likely to be male and on the organ donor register. 
- Australia: Significant associations with blood donor status were observed for: (1) organ donor registration $(\varphi=.25, p=.001)$, and (2) financial help $(\varphi=.17, \mathrm{p}=.022)$. Blood donors were more likely to be on the organ donor register and to have donated money.

At this simple level there are clear differences in the patterns of associations between the countries. The Italian sample, for example, was the only group where all of the other prosocial behaviours that were measured were associated with blood donor status. In addition, this country was the only one to show an association between a family tradition of philanthropy and blood donor status. Further, moral outrage was associated with blood donor status only in the USA. In contrast, a positive association between blood donor status and organ donor registration was observed across all six countries with an opt-in system (i.e., all countries other than Hungary).

Table 3 contains seven separate logistic regression models for each country. There is a consistency for organ donation registration, which is positively associated with blood donor status in all opt-in countries. Other than that there are cross-country differences, most clearly that moral outrage is linked to blood donor status only in the USA and a family tradition for helping is linked to blood donor status only in Italy. In a young student sample, males are more likely to report to be blood donors in England, Hungary and Malta. Older participants are more likely to report being blood donors in England, USA, the Netherlands and Australia. Financial helping is negatively associated with blood donor status in the Netherlands and positively in Australia.

\section{Discussion}

The results reported here show that when standard measures of blood donation and other philanthropic behaviours are given to similar samples (students) across countries that vary in blood donor practices and background philanthropic activity, both cross-cultural universals and differences in their associations emerge. We are able to offer some tentative explanations of these because of the consistency in the experimental methods used.

The most striking consistency observed across these countries is the association between the two health-related philanthropic behaviours: blood donation and organ donation registration. Specifically, for all countries with an opt-in system there is a significant positive association between blood donor status and organ donor registration. This implies that recruiting organ donors from blood donors, or vice-versa, is a distinct possibility. Indeed, in some countries like Australia blood donors are encouraged to become organ donors (see 
https://www.donateblood.com.au/learn/organ-tissue-donation). However, while associated, recent evidence suggests that blood donation and organ donation are distinct in terms of their cost to the individual [48]. Blood donation is seen as personally costly and posthumous organ donation is personally costless.

Interestingly, across these countries we did not see a consistent positive association between donor status and measures of non-health based philanthropy. This finding may be related to the argument that blood donors are saintly sinners [1] who give of themselves in a physical way (i.e., blood donation and/or organ donor registration), and, therefore, do not feel compelled to engage in other prosocial acts or even to do them less (i.e., financial philanthropy in the Netherlands). In essence, those who engage in health philanthropy may perceive themselves to be of high moral standing, which in turn offers some moral wiggle room in deciding whether one contributes to society in other ways. It may also be the case that some people give blood because it is financially cheaper or relatively less effortful than volunteering regularly. Also health based philanthropy, compared to non-health based philanthropy, is also a more personal and intimate giving.

Beyond these findings there are a number of interesting country specific effects. For example, the influence of family tradition for helping emerges as a predictor of blood donor status only in Italy. Italy is a country with a strong sense of family bonds and tradition, and families who carry out prosocial activities tend to encourage and support similar activities in their children [49-50]. Furthermore, the blood collection process is largely community-based via organizations such as Avis. Indeed, family influence is cited as a significant predictor of blood donation in Italy [51-52]. As such, this link in Italy, more than other countries, seems plausible and interpretable. Moral outrage was only associated with blood donor status in the USA. The American students scored the highest on moral outrage, suggesting that they may feel more aggrieved by perceived social unfairness and want to do something to help others out of pure altruism [53] or to alleviate the negative affect that they feel due to perceived injustice [54]. Another possibility is that the observed relationship reflects the high proportion of blood donors in the American sample. These participants may have been motivated by prior high school donor education campaigns which typically emphasize the small proportion of active donors in the community. Finally, our data also demonstrate contrasting effects across different countries such as the positive association between financial helping and blood donor status in Australia and a negative association in The Netherlands. University attendance is confounded with socio-economic status (SES) in 
Australia, such that those with a higher SES are over-represented in University samples [55] and University students tend to remain living at home for their first years of University attendance. As such, students in the Australian sample may have capacity to give both blood and money. This raises the possibility that SES may moderate the link between donating blood and money. However, a caveat is required here. The associations with financial philanthropy are small and inconsistent and the association with moral outrage again small and in one country only. Thus these need to be replicated and explored further.

\section{A Need for a Cross-Cultural Perspective}

We feel these findings demonstrate the importance of cross-cultural comparisons for understanding predictors of blood donation when developing cultural and country specific campaigns. For example, without the cross-cultural component a finding in one country (especially a hypothesized one such as the link between prosocial behaviour and moral outrage) may take on more weight when direct comparison to other countries is not possible. Conversely, while we observe that family tradition is important in Italy, such community and familial based giving may also be observed in other cultures. Thus, the cross-cultural comparison serves as a caveat about drawing too broad or too specific conclusions. That said, the positive link to organ donor registration is robust, generalizable and consistent across optin countries. The cross-cultural perspective also allows for subtle nuances in the concept of altruism to be explored. For example, in western samples altruism is equated with helping an anonymous stranger or group [56]. However, in BAME communities, altruism focuses on reciprocity within the community rather than helping strangers [57]. Further it has been argued, from the mechanisms of altruism approach (MOA) [1] that the 'altruism' of blood donation reflects a number of mechanisms one of which is warm-glow (impure altruism). This begs the question whether the association between warm-glow and blood donation is observed universally or if it is more important in particular cultural contexts.

Overall we feel these data show clearly that a cross-cultural perspective, based on standardized methods and procedures, is both achievable and can offer important insights. 


\section{References}

[1]. Ferguson E. Mechanisms of altruism approach to blood donor recruitment and retention: a review and future directions Trans Med. 2015; 25: 211-226.

DOI: $10.1111 /$ tme.12233

[2]. Ferguson E, Lawrence C. Blood donation and altruism: the mechanism of altruism approach. ISBT Science Series, 2015; 11: 148-157.

[3]. Ferguson E, Farrell K, Lawrence C. Blood Donation is an act of Benevolence Rather Than Altruism. Health Psychol. 2008; 27: 327-336. Doi. 10.1037/02786133.27.3.327

[4]. Ferguson E, Taylor M, Keatley D, Flynn, Lawrence C. Blood Donors' Helping Behavior is Driven by Warm Glow More Evidence For the Blood Donor Benevolence Hypothesis. Transfusion, 2012; 52: 2189-2200 Doi. 10.1111/j.15372995.2011.03557.x

[5]. Ferguson E, Lawrence C. It's Only Fair: Blood Donors are More Sensitive to Violations of Fairness Norms than Non-Donors - Converging Psychometric and Ultimatum Game Evidence. Vox Sang. 2018; 113: 424-450. Doi. 10.1111/vox.12636

[6]. Henrich J. Heine SJ, Norenzayan A. The weirdest people in the world? Behavior Brain Sci, 2010; 33: 61-83.

[7]. Johnson ND, Mislin AA. Trust games: A meta-analysis. J Econ Psychol. 2011; 32: 865889 DOI: $10.1016 /$ j.joep.2011.05.007

[8]. Mitkidis P, Xygalatas D, Buttrick N, Porubanova, Lienard P. The Impact of Authority on Cooperation: A Cross-Cultural Examination of Systemic Trust. Adapt Hum Behav Physiol, 2015; 1: 341-357, DOI: 10.1007/s40750-014-0011-3

[9]. Gächter S, Herrmann B. Reciprocity, culture and human cooperation: previous insights and a new cross-cultural experiment. Philos Trans Roy Soc Lon B, 2009; 364: 791806. DOI: $10.1098 /$ rstb.2008.0275 
[10]. Gächter S, Schulz J. Intrinsic honesty and the prevalence of rule violations across societies. Nature, 2016; 531: 496-499.

[11]. Henrich J, Boyd R, Bowles S, Camerer C, Fehr E, Gintis H, ... \& Henrich NS. "Economic man" in cross-cultural perspective: Behavioral experiments in 15 smallscale societies. Behav brain sci, 2005; 28: 795-815.

[12]. Herrmann B, Thöni C, Gächter S. Antisocial punishment across societies. Science, 2008; 319 1362-1367.

[13]. Floyd S, Rossi G, Baranova J, Blythe J, Dingemanse M, Kendrick KH, Zinken J Enfield NJ. Universals and cultural diversity in the expression of gratitude. Rol Soc Open Sci, 2018; 5; Article Number: 180391

DOI: $10.1098 /$ rsos. 180391

[14]. Kjell ONE, Nima,AA, Sikstrom S, Archer T, Garcia,D. Iranian and Swedish adolescents: differences in personality traits and well-being. PeerJ, 2013; Doi. 10.7717.peerj.197;

[15]. McCrea RR, Costa PT Jnr, Pilar GH, Rolland JP, Parker WD. Cross-cultural assessment of the five-factor mode: The revised NEO personality inventory. $J$ Cross-Cult Psychol, 1998; 29: 171-188.

[16]. Tran NY, Charbonneau J, Valderrama-Benitez V. Blood donation practices, motivations and beliefs in Montreal's Black communities: the modern gift under a new light. Ethnic Health, 2013; 18: 508-529.

[17]. Kim HS, Sasaki JY. Cultural Neuroscience: biology of the mind in cultural contexts. Ann Rev Psychol, 2014; 65: 487-514.

[18]. Mu Y, Kitayama S, Han S, Gelfand MJ. How culture gets embrained: Cultural differences in event-related potentials of social norm violations. Proc Nat Acad Sci, 2015; 112: 15348-15353.

[19]. Sharp C, Randhawa G. Altruism gift giving and reciprocity in organ donation: A review of the cultural perspectives and challenges of the concepts. Transplant Rev, 2014; 28: 163-168. Doi. 10.1016/j.trre.2014.05.001; 
[20]. Yun D, Park HS. Culture and the theory of planned behaviour: Organ donation intentions in Americans and Koreans. J Pacif Psychol, 2010; 4: 130-137. Doi. 10.1375/prp.4.2.130

[21]. Karacan E, Seval GC, Aktan Z, Ayli M, Palbiyikoglu R. Blood donors and factors impacting the blood donation decision: Motives for donating blood in Turkish sample. Transfu Apher Sci, 2013; 49: 468-473. Doi. 10.1016/j.transci.2013.04.044;

[22]. Olaiya MA, Alakija W, Ajala A, Olatunji RO. Knowledge, attitudes, beliefs and motivations towards blood donations among blood donors in Lagos, Nigeria. Trans Med, 2004;14:13-17.

[23]. Muthivhi TN, Olmsted MG, Park H, Sha M, Raju V, Mokoena T, ... Reddy R. Motivators and deterrents to blood donation among Black South Africans: a qualitative analysis of focus group data. Trans Med, 2015; 25: 249-258.

[24]. Belda Suarez IM, Fernández-Montoya A, Rodríguez Fernández A, López-Berrio, A, Cillero-Peñuela M. How regular blood donors explain their behavior. Transfusion, 2004; 44: 1441-1446.

[25]. Hupfer ME, Taylor DW, Letwin JA. Understanding Canadian student motivations and beliefs about giving blood. Transfusion, 2005; 45: 149-161

[26]. Glynn SA, Kleinman SH, Schreiber GB, Zuck T, Mc Combs S, Bethel J, ... \& Retrovirus Epidemiology Donor Study. Motivations to donate blood: demographic comparisons. Transfusion, 2002; 42: 216-225.

[27]. Steele WR, Schreiber GB, Guiltinan A, Nass C, Glynn SA, Wright DJ, ... \& Garratty G. The role of altruistic behavior, empathetic concern, and social responsibility motivation in blood donation behavior. Transfusion, 2008; 48: 43-55

[28]. Shaz BH, Demmons DG, Crittenden CP, Carnevale CV, Lee M, Burnett M, ... \& Hillyer CD. Motivators and barriers to blood donation in African American college students. Transfus Apher Sci, 2009; 41: 191-197.

[29]. Burzynski ES, Nam LS, Le Vior R. Barriers and motivations to voluntary blood donation in sub-Saharan African settings; a literature review. ISBT Science Series, 2016; 11: 73-81 
[30]. Bednall TC, \& Bove LL. Donating blood: A meta-analytic review of self-reported motivators and deterrents. Trans Med Revs, 2011; 25: 317-334.

[31]. Merz E-M, van den Hurk K, de Kort, WLAM.. Donation Registration and Decision Making Among Current Blood Donors in the Netherlands. Prog Transplant, 2017; 27: 266-272. Doi.10.1177/1526924817715470

[32]. Meslin EM, Rooney PM, Wolf JG. Health-related philanthropy: Toward understanding the relationship between the donation of the body (and its parts) and traditional forms of philanthropic giving. Nonprof Volunt Sect, 2008; 37: 44S-62S.

[33]. Bekkers R. Traditional and health-related philanthropy: The role of resources and personality. Social Psychology Quarterly 2006; 69: 349-366.

[34]. Reed II, Kay A, Finnel S, Aquino K, Levy E. I don't want the money, I just want your time: How moral identity overcomes the aversion to giving time to prosocial causes. J Per Soc Psychol, 2016;110: 435457. https://doi.org/10.1037/pspp0000058

[35]. Bekkers R. Charity begins at home: How socialization experiences influence giving and volunteering. 2005; downloaded 07-09-2017 University of Groningen

[36]. van Doorn J, Zeelenberg M. Anger and prosocial behavior. Emot Rev, 2014; 6: 261-268

[37]. Montada L, Schneider A. Justices and emotional reactions to the disadvantages Soc Justice Res, 1989; 3; 313-341

[38]. Lotz S, Okimoto TG, Schlösser T, Fetchenhauer D. Punitive versus compensatory reactions to injustice: Emotional antecedents to third-party interventions. J Exp Soc Psychol, 2011; 47: 477-480. DOI: 10.1016/j.jesp.2010.10.004

[39]. Thulin EW, Bicchieri C. I'm so angry I could help you: Moral outrage as a driver of victim compensation. Soc Philos Policy, 2016; 32; 146-160. DOI: $10.1017 / \mathrm{S} 0265052516000145$

[40]. van de Vyver J, Abrams D. Testing the prosocial effectiveness of the prototypical moral emotions: elevation increases benevolent behaviors and outrage increases justice behaviors. J Exp Soc Psychol, 2015; 58: 23-33. doi, 10.1016/j.jesp.2014.12.005

[41]. World Giving Index (2017). https://www.cafonline.org/docs/default-source/about-uspublications/cafworldgivingindex2017_2167a_web_210917.pdf?sfvrsn=ed1dac40_1 $\underline{0})$. 
[42]. Crump, M.J.C., McDonnell, J. V., \& Gureckis, T. M. (2013). Evaluating Amazon's Mechanical Turk as a Tool for Experimental Behavioral Research, PLoS One, 8, e57410. doi: 10.1371/journal.pone.0057410

[43]. van de Looij-Jansen PM, Jan de Wilde E. Comparison of Web-Based versus Paper-andPencil Self-Administered Questionnaire: Effects on Health Indicators in Dutch Adolescents. Health services Research, 2008; 43: 1708-1721.

[44]. Bertalli NA, Allen KJ, McLaren CE, Turkovic L, Osborne NJ, Constantine CC, Delatycki MB, English DR, Giles GG, Hopper JL, Anderson GJ, Olynyk JK, Powell LW, Gurrin LC for the Health Iron Study Investigators. A comparison of selfreported and record-linked blood donation history in an Australian cohort. Transfusion, 2011; 51:2189-2198. DOI. 10.1111/j.1537-2995.2011.03141.x

[45]. Bekkers R, Wiepking P. Accuracy of self-reports on donations to charitable organizations. Qual Quant, 2001; 45: 1369-1383. DOI: 10.1007/s11135-010-93419.

[46]. Shepherd L, O'Carrol RE, Ferguson E. An international comparison of deceased and living organ donation/transplant rates in opt-in and opt-out systems: a panel study. BMC Medicine. 2014; 12: 131.

[47]. Beugre CD. Development and validation of a Deontic Justice Scale. J Appl Soc Psychol, 2012; 42: 2163-2190, DOI 10.1111/j.1559-1816.2012.00935.x

[48]. Ferguson E, Zhao K, O'Carroll RE, Smillie LD. Costless and Costly Pro-Sociality: Correspondence among Personality Traits, Economic Preferences, and Real World Pro-Sociality. Soc Psychol Pers Sci (in press)

[49]. Marta E, Pozzi M, Marzana D. Volunteers and ex-volunteers. Paths to civic engagement through volunteerism, Psycké, 2010; 19: 5-17. DOI:10.4067/S07182228201000020000194

[50]. Scabini E, Marta E, Lanz M. (2006) Transition to adulthood and family relations: An intergenerational perspective. London: Psychology Press

[51]. Bani M, Strepparava MG. (2011). Motivation in Italian whole blood donors and the role of commitment. Psychol Health Med, 2011; 16: 641-

649. DOI: $10.1080 / 13548506.2011 .569731$ 
[52]. Zito E, Alfieri S, Marconi M, Saturni V, Cremonesi G. Adolescents and blood donation: motivations, hurdles and possible recruitment strategies. Blood Transfusion, 2012; 10: 45-58. DOI: 10.2450/2011.0090-10.

[53]. Batson CD. (1991). The altruism question: Toward a social-psychological answer. Hillsdale, NJ: Erlbaum.

[54]. Cialdini RB, Brown SL, Lewis BP, Luce C, Neuberg SL. Reinterpreting the empathyaltruism relationship: when one into one equals oneness. J Pers Soc Psychol, 1997; 73: 481-494.

[55]. DEEWR (Department of Education Employment and Workplace Relations). (2008). Review of Australian Higher Education. Canberra: DEEWR

[56]. Ma L, Tunney R, Ferguson E. Does Gratitude Enhance Prosociality: A Meta-Analytic Review. Psychol Bull, 2017; 143: 601-635. DOI: 10.1037/bul0000103

[57]. Tran NY, Charbonneau J, Valderrama-Benitez V. Blood donation practices, motivations and beliefs in Montreal's block communities; the modern gift under a new light. Ethnic Health, 2013; 18; 508-529.Doi. 10.1080/13557858.2012.734279 
Table 1: Blood Donation Systems, Organ Donor Default, World Giving Index, and GDP by Country

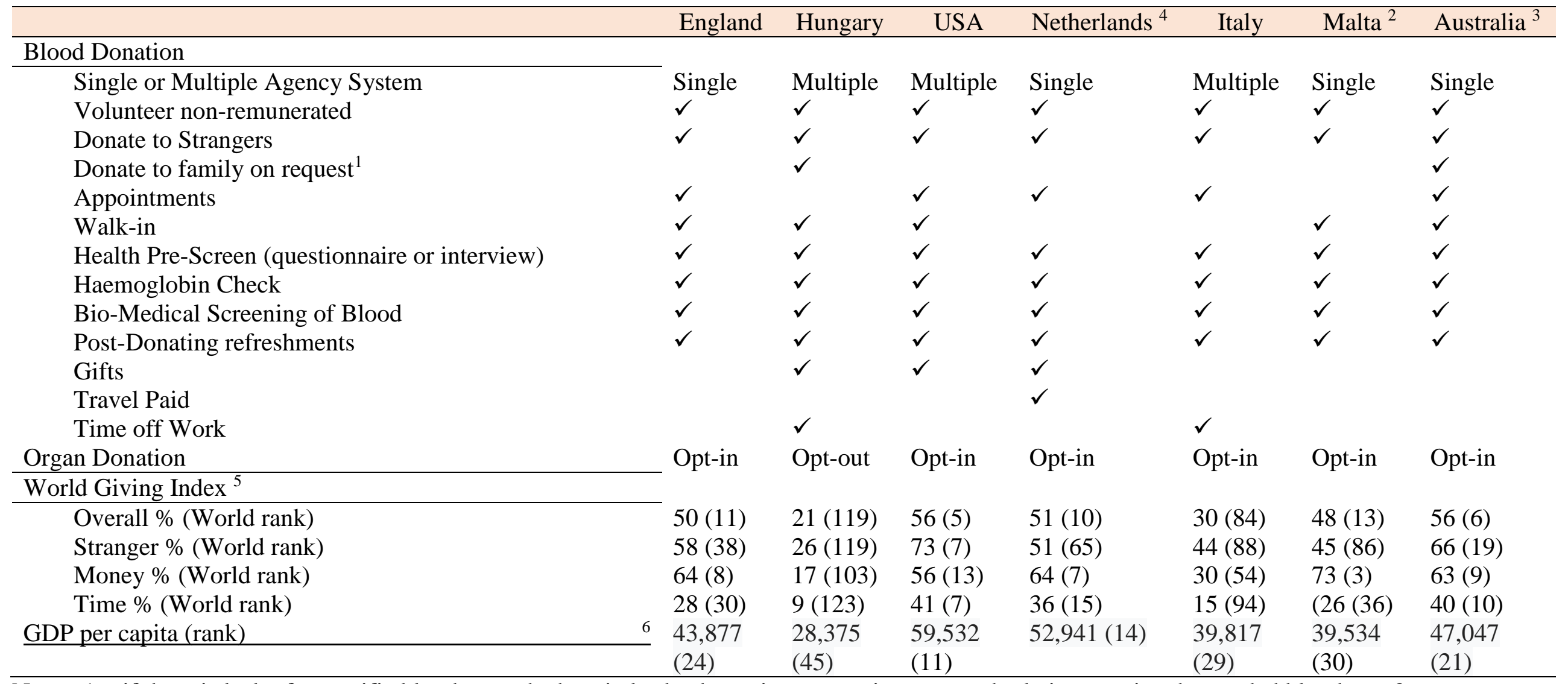

Notes. $1=$ if there is lack of a specific blood type, the hospital asks the patients acquaintances and relatives to give the needed blood typ. $2=$ Walk ins in Malta are generally at the National Blood Transfusion centre, appointments are used for single platelet donors. $3=$ Walk in's possible but rare. $4=$ Travel paid as requested by the donor with specific regulations about what is refundable. $5=$ World giving index (https://www.cafonline.org/docs/default-source/about-us-publications/cafworldgivingindex2017_2167a_web_210917.pdf?sfvrsn=ed1dac40_10). 6 = Data from the World Bank 2017 
Table 2. Descriptives for the Seven Countries

\begin{tabular}{|c|c|c|c|c|c|c|c|c|}
\hline & & England & Hungary & USA & Netherlands & Italy & Malta & Australia \\
\hline Age & (years) & $\begin{array}{c}22.9 \\
(\mathrm{SD}=2.9)\end{array}$ & $\begin{array}{c}20.6 \\
(\mathrm{SD}=1.9)\end{array}$ & $\begin{array}{c}18.8 \\
(\mathrm{SD}=1.9)\end{array}$ & $\begin{array}{c}19.7 \\
(\mathrm{SD}=2)\end{array}$ & $\begin{array}{c}20.8 \\
(\mathrm{SD}=2.3)\end{array}$ & $\begin{array}{c}21.5 \\
(\mathrm{SD}=5.6)\end{array}$ & $\begin{array}{c}20.8 \\
(\mathrm{SD}=5.7)\end{array}$ \\
\hline Sex & (\% female) & $45.8 \%$ & $63.3 \%$ & $74.3 \%$ & $78.3 \%$ & $74.8 \%$ & $76.2 \%$ & $63.7 \%$ \\
\hline Blood Donor & (\% yes) & $25.8 \%$ & $31.6 \%$ & $34 \%$ & $11.1 \%$ & $24.8 \%$ & $28.2 \%$ & $23.1 \%$ \\
\hline Organ Donor & (\% yes) & $46.1 \%$ & $\mathrm{~N} / \mathrm{A}$ & $75.3 \%$ & $36.1 \%$ & $8.7 \%$ & $23.3 \%$ & $16.5 \%$ \\
\hline $\begin{array}{l}\text { Family } \\
\text { tradition }\end{array}$ & (\% yes) & $38.2 \%$ & $37.2 \%$ & $37.2 \%$ & $35.2 \%$ & $36.2 \%$ & $23.3 \%$ & $39.0 \%$ \\
\hline $\begin{array}{l}\text { Effortful } \\
\text { helping }\end{array}$ & (\% yes) & $88.2 \%$ & $75.8 \%$ & $94.9 \%$ & $80.7 \%$ & $86.5 \%$ & $86.6 \%$ & $91.2 \%$ \\
\hline $\begin{array}{l}\text { Financial } \\
\text { help }\end{array}$ & (\% yes) & $80.4 \%$ & $61.2 \%$ & $74.3 \%$ & $58.4 \%$ & $30.3 \%$ & $77.7 \%$ & $66.3 \%$ \\
\hline $\begin{array}{l}\text { Moral } \\
\text { Outrage }\end{array}$ & & $\begin{array}{c}17.3(\mathrm{SD}= \\
3.2)\end{array}$ & $\begin{array}{c}17.4(\mathrm{SD}= \\
2.8)\end{array}$ & $\begin{array}{c}18.4(\mathrm{SD}= \\
2.6)\end{array}$ & $\begin{array}{c}16.5(\mathrm{SD}= \\
2.8)\end{array}$ & $\begin{array}{c}16.3(\mathrm{SD}= \\
3.2)\end{array}$ & $\begin{array}{c}17.8(\mathrm{SD}= \\
3.1)\end{array}$ & $\begin{array}{c}17.2(\mathrm{SD}= \\
2.8)\end{array}$ \\
\hline Ns & & 305 & 215 & $454-470$ & 332 & $304-310$ & $200-202$ & $181-182$ \\
\hline Collection & & University of & Eszterházy & Ohio & Tilburg & Catholic & The & The \\
\hline Site & & Nottingham & $\begin{array}{c}\text { Károly } \\
\text { University }\end{array}$ & University & University & $\begin{array}{c}\text { University of } \\
\text { the Sacred } \\
\text { Heart Milan }\end{array}$ & $\begin{array}{c}\text { University of } \\
\text { Malta }\end{array}$ & $\begin{array}{c}\text { University of } \\
\text { Queensland }\end{array}$ \\
\hline $\begin{array}{l}\text { Mode of } \\
\text { Delivery }\end{array}$ & & $\begin{array}{c}\text { Paper \& } \\
\text { Pencil }\end{array}$ & $\begin{array}{c}\text { Paper \& } \\
\text { Pencil }\end{array}$ & $\begin{array}{l}\text { Qualtrics } \\
\text { Online }\end{array}$ & $\begin{array}{l}\text { Qualtrics } \\
\text { Online }\end{array}$ & $\begin{array}{c}\text { Paper \& } \\
\text { Pencil }\end{array}$ & $\begin{array}{c}\text { Paper \& } \\
\text { Pencil }\end{array}$ & $\begin{array}{l}\text { Qualtrics } \\
\text { Online }\end{array}$ \\
\hline
\end{tabular}

Note: N/A = not applicable 
Table 3. Logistic Regression Models for the Seven Countries

\begin{tabular}{|c|c|c|c|c|c|c|c|c|c|c|c|c|c|c|}
\hline & \multicolumn{3}{|c|}{ England } & \multirow{2}{*}{$\begin{array}{c}\text { Hungary } \\
O R\end{array}$} & \multicolumn{2}{|c|}{ USA } & \multicolumn{2}{|c|}{ Netherlands } & \multicolumn{2}{|c|}{ Italy } & \multicolumn{2}{|c|}{ Malta } & \multicolumn{2}{|c|}{ Australia } \\
\hline & $B$ & OR & $B$ & & $B$ & OR & $B$ & $O R$ & $B$ & OR & $B$ & $O R$ & $B$ & $O R$ \\
\hline Sex & $0.93 * * *$ & $\begin{array}{l}2.53 \\
(1.41,4.54)\end{array}$ & 0.82* & $\begin{array}{l}2.26 \\
(1.19,4.2)\end{array}$ & 0.29 & $\begin{array}{l}1.33 \\
(0.81,2.2)\end{array}$ & 01.4 & $\begin{array}{l}1.15 \\
(0.47,2.7)\end{array}$ & -0.002 & $\begin{array}{l}1.00 \\
(0.50,2.00)\end{array}$ & $1.56 * *$ & $\begin{array}{l}4.78 \\
(1.96,11.6)\end{array}$ & 0.62 & $\begin{array}{l}1.85 \\
(0.81,4.24)\end{array}$ \\
\hline Age & $0.15^{* * *}$ & $\begin{array}{l}1.16 \\
(1.96,1.27)\end{array}$ & 0.09 & $\begin{array}{l}1.09 \\
(0.94,1.2)\end{array}$ & $0.15 *$ & $\begin{array}{l}1.16 \\
(1.01,1.4)\end{array}$ & 0.19* & $\begin{array}{l}1.21 \\
(1.04,1.4)\end{array}$ & $-0.27 * *$ & $\begin{array}{l}0.78 \\
(0.64,0.91)\end{array}$ & 0.002 & $\begin{array}{l}1.00 \\
(0.95,1.06)\end{array}$ & 0.08* & $\begin{array}{l}1.08 \\
(1.02,1.15)\end{array}$ \\
\hline $\begin{array}{l}\text { Organ } \\
\text { Donor }\end{array}$ & $0.68 * * *$ & $\begin{array}{l}2.00 \\
(1.13,3.54)\end{array}$ & & & 0.70 ** & $\begin{array}{l}2.00 \\
(1.19,3.3)\end{array}$ & $1.17 * *$ & $\begin{array}{l}3.22 \\
(1.54,6.7)\end{array}$ & $1.30 * *$ & $\begin{array}{l}3.69 \\
(1.45,9.37)\end{array}$ & $1.62 * * *$ & $\begin{array}{l}5.03 \\
(2.18,11.6)\end{array}$ & $1.16 *$ & $\begin{array}{l}3.20 \\
(1.28,7.99)\end{array}$ \\
\hline $\begin{array}{l}\text { Family } \\
\text { tradition }\end{array}$ & 0.04 & $\begin{array}{l}1.04 \\
(0.59,1.83)\end{array}$ & -0.24 & $\begin{array}{l}0.79 \\
(0.41,1.5)\end{array}$ & 0.32 & $\begin{array}{l}1.37 \\
(0.91,2.0)\end{array}$ & 0.55 & $\begin{array}{l}1.73 \\
(0.81,3.6)\end{array}$ & $0.85 * *$ & $\begin{array}{l}2.33 \\
(1.30,4.16)\end{array}$ & -0.03 & $\begin{array}{l}0.97 \\
(0.41,2.30)\end{array}$ & 0.43 & $\begin{array}{l}1.54 \\
(0.71,3.34)\end{array}$ \\
\hline $\begin{array}{l}\text { Effortful } \\
\text { helping }\end{array}$ & 1.03 & $\begin{array}{l}2.79 \\
(0.89,8.87)\end{array}$ & -0.37 & $\begin{array}{l}0.69 \\
(0.33,1.4)\end{array}$ & 0.30 & $\begin{array}{l}1.35 \\
(0.45,4.0)\end{array}$ & 0.19 & $\begin{array}{l}1.21 \\
(0.53,3.3)\end{array}$ & 1.25 & $\begin{array}{l}3.49 \\
(0.98,12.4)\end{array}$ & 1.28 & $\begin{array}{l}3.60 \\
(0.92,14.0)\end{array}$ & 0.39 & $\begin{array}{l}1.48 \\
(0.34,6.45)\end{array}$ \\
\hline $\begin{array}{l}\text { Financial } \\
\text { help }\end{array}$ & 0.42 & $\begin{array}{l}1.52 \\
(0.70,3.28)\end{array}$ & -0.21 & $\begin{array}{l}0.81 \\
(0.43,1.5)\end{array}$ & -0.06 & $\begin{array}{l}0.94 \\
(0.56,1.6)\end{array}$ & $-0.86 *$ & $\begin{array}{l}0.42 \\
(0.20,0.8)\end{array}$ & 0.31 & 1.40 & 0.30 & $\begin{array}{l}1.35 \\
(0.54,3.38)\end{array}$ & $1.12 *$ & $\begin{array}{l}3.08 \\
(1.16,8.12)\end{array}$ \\
\hline $\begin{array}{l}\text { Moral } \\
\text { Outrage }\end{array}$ & 0.06 & $\begin{array}{l}1.07 \\
(0.96,1.18)\end{array}$ & 0.04 & $\begin{array}{l}1.04(0.92, \\
1.18)\end{array}$ & $0.10 *$ & $\begin{array}{l}1.10 \\
(1.00,1.2)\end{array}$ & -0.03 & $\begin{array}{l}0.08 \\
(0.85,1.1)\end{array}$ & 0.05 & $\begin{array}{l}0.36 \\
(0.95,1.16)\end{array}$ & 0.14 & $\begin{array}{l}1.15 \\
(0.99,1.33)\end{array}$ & -0.12 & $\begin{array}{l}0.88 \\
(0.76,1.02)\end{array}$ \\
\hline Constant & $-7.79 *$ & & -3.23 & & & -6.26 & & -5.77 & & 1.98 & -6.03 & & -2.72 & \\
\hline $\mathrm{N}$ & 304 & & 215 & & 445 & & 332 & & 302 & & 200 & & 181 & \\
\hline $\mathrm{R}^{2}$ & .15 & & 12 & & .08 & & .13 & & .16 & & .20 & & .21 & \\
\hline
\end{tabular}

Note: $* p<.05, * * p<.01, * * * p<.001$ : Sex $(0=$ female, $1=$ male $)$. Organ donor, Family tradition, Effortful helping, Financial help $($ all $0=$ no, $1=$ yes) 